\title{
A Taxonomic Study of Certain Bacteria Currently Classified as Vibrio Species
}

\author{
By G. H. G. DAVIS AND R. W. A. PARK* \\ Department of Bacteriology, University of Birmingham
}

(Received 28 April 1961)

\section{SUMMARY}

Twenty-five strains currently classified into 14 serological types or species of the genus Vibrio obtained from the NCIB and NCTC have been studied in detail for morphological, cultural and biochemical characters in two independent studies. The results indicate that these strains include members of three distinct taxonomic groups or genera, Vibrio, Pseudomonas and Comamonas. The new generic name Comamonas, type species $C$. percolans, replaces Lophomonas (Galarneault \& Leifson) which is invalid.

\section{INTRODUCTION}

Thirty-four species are listed in the genus Vibrio of Bergey's Manual (1957). These species are so heterogeneous in character that it is impossible to define the genus in exclusive terms.

In recent years several new diagnostic tests have been developed for use in bacterial classification, especially of the Gram-negative, polarly flagellate bacteria. By applying a large range of tests to a small number of strains of so-called vibrios, we hoped to clarify the characters of the genus Vibrio and appraise the true taxonomic relationships of certain species at present included in the genus.

The work to be described was carried out as independent studies by the two authors. One of us (R.W.A.P.) examined a group of vibrios as part of a comparative study of the polarly flagellate bacteria commonly found in surface waters (see Park, 1961 a). The other (G.H.G.D.) was asked by Dr R. Cain to determine the taxonomic relationships of a so-called vibrio (vibrio 01, Happold \& Key, 1932) commonly used in biochemical studies, e.g. Cain (1961). In order to do this a number of other vibrio strains were obtained for comparative study. Although basically similar, the two studies differ in the tests, techniques and strains used and sometimes in the results obtained, but, as we hope to show, the conclusions which can be drawn from both studies are in good agreement. The simplest way of presenting our information is to divide each of the sections of this paper dealing with Methods and Results into two parts, distinguished by the initials of the author concerned.

METHODS. 1. (R.W.A.P.)

Strains examined

Vibrio comma (Inaba), NCTC 4693.

Vibrio sp. (Gardner \& Venkatraman group III), NCTC 4711.

Vibrio sp. (Gardner \& Venkatraman group V), NCTC 4715.

* Present address: Department of Microbiology, Reading University. 
Vibrio sp. (Gardner \& Venkatraman group VI), NCTC 4716.

Vibrio sp. (Gardner \& Venkatraman group II), NCTC 8042.

V. eltor NCTC 5395.

$V$. paracholerae (Gardner \& Venkatraman group III), NCTC 30.

$V$. alcaligenes (Lehmann \& Neumann, 1931), NCTC 9239.

$V$. percolans (Mudd \& Warren, 1923), NCTC 1937.

$V$. proteus (Buchner, 1885), NCTC 8563.

$V$. cuneatus (Gray \& Thornton, 1928), NCIB 8194.

V. cyclosites (Gray \& Thornton, 1928), NCIB 2581.

$V$. neocistes (Gray \& Thornton, 1928), NCIB 2582.

Vibrio 01 (Happold \& Key, 1932), NCIB 8250.

\section{Strain maintenance}

Stock cultures were grown $24 \mathrm{hr}$. on nutrient agar slopes in loosely closed screwcapped bottles and stored at room temperature with the caps screwed down; fresh cultures were prepared monthly.

Incubation at $30^{\circ}$ was used throughout this study, except in certain tests as indicated. Storage at room temperature was necessary because Vibrio comma does not survive well at low temperatures, e.g. $4^{\circ}$.

\section{Characters examined}

1. Cell-form and Gram-reaction of $24 \mathrm{hr}$. nutrient agar growth.

2. Occurrence and type of motility in hanging-drop preparations of $18 \mathrm{hr}$. peptone water culture.

3. Disposition and number of flagella using electron microscopy.

4. Metabolism of carbohydrates:

(i) Acid and gas production from the following carbohydrates: DL-arabinose, D-glucose, D-fructose, D-mannose, D-galactose, mannitol, dulcitol, sorbitol, sucrose lactose, maltose, salicin; tested in $1 \%(\mathrm{w} / \mathrm{v})$ concentration in peptone water (Mackie $\&$ McCartney, 1953) and also in a dilute meat extract medium (Simon, 1956), both media containing bromothymol blue as $\mathrm{pH}$ indicator. Arabinose was added as a Seitz-filtered solution to sterile base: gas production from this sugar was not tested for. All other carbohydrate media were steam sterilized. Control tests without carbohydrate were also inoculated. Initial $\mathrm{pH}$ of all tests was $7 \cdot 4$, and tests were read after $24 \mathrm{hr}$. and 7 days' incubation. As results were identical by both methods, only one set has been recorded.

(ii) Utilization of carbohydrates as sole carbon sources. Tested upon following medium (\%, w/v): $\mathrm{NH}_{4} \mathrm{Cl}, 0.1 ; \mathrm{K}_{2} \mathrm{HPO}_{4}, 0.1 ; \mathrm{MgSO}_{4}, 0.05$; agar, 1.5. Same carbohydrates used as in (i) above, at same concentration, all added as Seitz-filtered solutions. Utilization was inferred from the growth of an organism within 7 days in two successive subcultures. Controls without carbohydrate were included.

(iii) Oxidation versus fermentation of glucose; test as described by Hugh \& Leifson (1953), initial $\mathrm{pH} 7 \cdot 4$.

(iv) Production of reducing compounds from gluconate (Haynes, 1951). Medium $(\%, w / v)$ : Oxoid peptone, $0 \cdot 2 ;$ Oxoid yeast extract, $0 \cdot 1 ; \mathrm{K}_{2} \mathrm{HPO}_{4}, 0.1 ; \mathrm{pH} 7 \cdot 0$. Basal medium autoclaved and Seitz-filtered $40 \%(\mathrm{w} / \mathrm{v})$ aqueous potassium gluconate 
solution added to give final concentration of $4 \%(w / v)$. Dispensed aseptically, inoculated and shaken by hand twice daily during 5 days' incubation. Tested with Benedict's qualitative reagent.

(v) Acetylmethylcarbinol production from glucose, using Barritt's (1936) method, but incubated for 5 days.

(vi) Methyl-red test after 5 days' incubation (Mackie \& McCartney, 1953).

(vii) Modified Eijkman test (Topley \& Wilson's Principles, 1955).

(viii) Hydrolysis of starch within 5 days, tested upon nutrient agar containing $0.2 \%(w / v)$ soluble starch by flooding with iodine solution (Allen, 1918).

5. Nitrate reduction, tested in 5-day-old peptone water cultures containing $0.1 \%(\mathrm{w} / \mathrm{v}) \mathrm{KNO}_{3}$, using the Griess-Ilosvay reagents and zinc powder test for false negatives (ZoBell, 1932).

6. Cholera-red reaction, tested by adding conc. $\mathrm{H}_{2} \mathrm{SO}_{4}(0.5 \mathrm{ml}$.) to a 5-day old culture in peptone water containing $0.001 \%(\mathrm{w} / \mathrm{v}) \mathrm{KNO}_{3}$ (Beam, 1959).

7. Indole production, tested in 5-day-old peptone (Oxoid) water cultures using Ehrlich reagent and ether extraction.

8. Utilization of tryptophan, phenylalanine, phenol, benzoic acid, and catechol as sole carbon sources. Compounds were supplied in $0.1 \%(\mathrm{w} / \mathrm{v})$ concentration in the inorganic base described in 4 (ii) above. (Note: phenol was used in $0.05 \%$ $(\mathrm{w} / \mathrm{v})$ as $0.1 \%$ inhibited certain strains; autoxidation of catechol by light, heat or high $\mathrm{pH}$ was avoided by adjusting basal medium to $\mathrm{pH} 6.5$ and sterilizing by Seitz-filtration.)

9. Tyrosine breakdown, tested by the ability to dissolve tyrosine $(0.5 \%, w / v)$ suspended in nutrient agar within 7 days.

10. Phenylalanine and malonate breakdown, tested by the method of Shaw \& Clarke (1955).

11. Gelatin hydrolysis, using $0.5 \%(\mathrm{w} / \mathrm{v})$ gelatin in nutrient agar and flooding 5-day growth with acid mercuric chloride (Frazier, 1926).

12. Serum hydrolysis, observed after $24 \mathrm{hr}$. and 7 days' growth upon inspissated serum.

13. Casein hydrolysis, using Hastings' (1904) method with $10 \%$ (v/v) skimmed milk in nutrient agar; examined after 5 days.

14. Hydrogen sulphide production from peptone water, detected with lead acetate paper; examined after $24 \mathrm{hr}$. and 7 days.

15. Urea breakdown within 7 days, using Christensen (1946) medium in liquid form. Controls without area were included.

16. Tributyrin hydrolysis, detected by clearing of $0.2 \%(\mathrm{v} / \mathrm{v})$ tributyrin in nutrient agar after $24 \mathrm{hr}$. and 7 days.

17. Utilization of organic acids as sole carbon sources, inferred from growth within 7 days in two successive subcultures upon the inorganic medium described in 4 (ii) above containing $0.25 \%(w / v)$ of acid. Tested: succinic, malic, acetic, citric, pyruvic, lactic, malonic, and formic acids, all supplied as Seitz-filtered solutions of the sodium salts.

18. Utilization of ethanol and production of excess acid was tested by growth within 7 days in two successive subcultures upon inorganic medium (4 ii above) containing $1 \%(w / v)$ calcium carbonate and $1 \%(v / v)$ ethanol. Excess acid production was shown by clearing of $\mathrm{CaCO}_{3}$ around growth. Controls without ethanol 
were incubated separately. (Note: this is not the test of Shimwell, Carr \& Rhodes, 1960, as used by G. H. G. D., Methods, 2.)

19. Catalase production, tested with 10 vol. $\mathrm{H}_{2} \mathrm{O}_{2}$ upon $24 \mathrm{hr}$. nutrient agar growth.

20. Kovacs (1956) oxidase test.

21. Cytochrome oxidase test of Gaby \& Hadley (1957).

22. Growth in peptone water at $0^{\circ}$ (within 14 days), $30^{\circ}, 37^{\circ}, 42^{\circ}, 45^{\circ}$ (within 7 days). Tested twice.

23. Sodium chloride tolerance, tested by growth within 7 days in peptone water containing $0.5,1,3,6$ or $9 \%(w / v) ~ N a C l$. Tested in triplicate.

24. Growth upon MacConkey agar (Oxoid) and Aronson (pH 9) medium (Mackie \& McCartney, 1953) within 7 days.

25. Pyocyanin production. In addition to routine observation of all cultures, 7-day growth upon the glycerol-peptone medium of Gessard (1891) was examined for diffusible pigment in daylight and under a source of ultraviolet radiation fitted with a Wood's glass (u.v.).

26. Fluorescin production. In addition to routine observation, strains were tested for this character in the medium of Georgia \& Poe (1931) and upon the inorganic base described in 4 (ii) above containing $\mathrm{D}$-glucose $(1 \%, \mathrm{w} / \mathrm{v})$ and $\mathrm{CaCO}_{3}$ $(1 \%, w / v)$. Cultures were examined after 1,3 , and 7 days in daylight and under u.v.

27. Resistance to antibacterial agents. Tested: penicillin, $2 \cdot 5$ i.u.; Terramycin, $10 \mu \mathrm{g}$.; streptomycin, $80 \mu \mathrm{g}$.; chloramphenicol, $100 \mu \mathrm{g}$., and 2:4-diamino 6:7-diisopropyl pteridine (vibriostatic agent $\mathrm{O} / 129$ ). Inhibition of growth at $24 \mathrm{hr}$. by these substances was tested upon nutrient agar seeded with organisms using Evans 'Sentest' disks (antibiotics) or, in the case of $0 / 129$, a few crystals placed upon the agar surface.

METHODS. 2. (G.H.G.D.)

Strains examined

Vibrio comma, NCTC 4693, NCTC 6585, NCTC 7270, NCTC 8021, NCTC 8367.

$V$. percolans, NCIB 8193.

$V$. cuneatus, NCIB 8194.

V. cyclosites, NCIB 2581.

$V$. neocistes NCIB 2582.

$V .01$, NCIB 8250.

\section{Strain maintenance}

As R.W.A.P., but using cotton-wool-plugged tubes and subcultured every 2 weeks.

\section{Characters examined}

1. Cell-form and Gram-reaction, as R.W.A.P.

2. Motility in nutrient broth at $\mathbf{2 5}^{\circ}$, observed by phase-contrast microscopy after 1-3 days.

3. Flagellation, as R.W.A.P., and various staining methods.

4. Carbohydrate metabolism:

(i) Acid production. Basal medium: Koser salt solution (Mackie \& McCartney, 1953, p. 429) plus Oxoid yeast extract $0.8 \%(\mathrm{w} / \mathrm{v})$. Initial $\mathrm{pH}$ adjusted to $7 \cdot 0$, $2 \mathrm{ml}$. of $1.5 \%(\mathrm{w} / \mathrm{v})$ solution of bromocresol purple added per litre and medium 
autoclaved. Carbohydrates were added as $20 \%(w / v)$ autoclaved solutions to give $1 \%(w / v)$ final concentration. The complete media were aseptically dispensed and tested for sterility by incubating for $48 \mathrm{hr}$. at $30^{\circ}$. Carbohydrates used: arabinose $(\mathrm{L}+)$, xylose, glucose, fructose, mannose, galactose, rhamnose, mannitol, sorbitol, dulcitol, inositol, sucrose, maltose, lactose melibiose, raffinose, dextrin, inulin, glycogen, salicin. Tests read daily over 14 days.

(ii) Oxidation versus fermentation of glucose. Modified from Hugh \& Leifson (1953). Basal medium as in (i) above, plus $1 \%(w / v)$ glucose and $0 \cdot 3 \%(w / v)$ agar. Initial $\mathrm{pH} 7 \cdot 0$ and $2 \mathrm{ml}$. of $1.5 \%(\mathrm{w} / \mathrm{v})$ bromocresol purple added per litre. (Note: these modifications were recommended by $\mathrm{Dr}$ A. C. Hayward, Commonwealth Mycological Institute, Kew, and Dr A. C. Baird-Parker, Unilever, Bedford, and do appear to clarify the results of this test.)

(iii) Gas from glucose, in addition to observations of (ii) above, routine peptone water fermentation tests containing Durham tubes were observed over 14 days.

(iv) Voges-Proskauer and methyl-red tests as Mackie \& McCartney (1953).

(v) Acetylmethylcarbinol (acetoin) production and final $\mathrm{pH}$ from $1 \%(\mathrm{w} / \mathrm{v})$ glucose in the basal medium of (i) above, initial pH 7.0. Tested after 4 days using pH test papers and Barritt's (1936) method for acetylmethylcarbinol.

(vi) Starch hydrolysis, as R.W.A.P.

(vii) Aesculin hydrolysis within 7 days in the basal medium of (i) above, plus $0.5 \%(w / v)$ aesculin and $0.005 \%(w / v)$ ferric ammonium citrate.

(viii) Dihydroxyacetone production from glycerol, test of Shimwell, Carr \& Rhodes (1960).

5. Nitrate reduction: Basal medium 4 (i) above plus $0 \cdot 1 \%(\mathrm{w} / \mathrm{v}) \mathrm{KNO}_{3}$ and $0 \cdot 1 \%(w / v)$ agar. Procedure as R.W.A.P.

6. Cholera-red test, in Oxoid peptone water (Mackie \& McCartney, 1953).

7. Indole production, in $1 \%(w / v)$ Oxoid tryptone water, tested after 3 days by ether extraction and Ehrlich reagent.

8. Tyrosine breakdown, as R.W.A.P.

9. Gelatin hydrolysis, as R.W.A.P., but using $\mathbf{0 \cdot 2} \%(\mathrm{w} / \mathrm{v})$ gelatin.

10. Serum hydrolysis, as R.W.A.P.

11. Casein hydrolysis, as R.W.A.P.

12. Lysine decarboxylase activity. Method of Carlquist (1956). Medium: Basal medium of $4(\mathrm{i})$ above plus $0.5 \%(\mathrm{w} / \mathrm{v})$ lysine hydrochloride. Tested after 5 days.

13. Hide-powder lysis. Method of Evans (1947) in double-layer plates of basal medium 4(i) above with hide-powder (Baird \& Tatlock) incorporated in top layer. Examined daily.

14. Hydrogen sulphide production. Basal medium of 4 (i) above, plus (i) $0.05 \%(w / v)$ L-cysteine-HCl, or (ii) $0.1 \%(w / v)$ sodium thiosulphate. $\mathbf{H}_{2} \mathrm{~S}$ detected by lead acetate paper, over 7 days.

15. Ammonia production from arginine. Medium: (\%,w/v), Oxoid tryptone, $0.2 ; \mathrm{NaCl}, 0.5 ; \mathrm{K}_{2} \mathrm{HPO}_{4}, 0.03 ;$ L-arginine-HCl, $0.5 ;$ glucose, $0.1 ; \mathrm{pH} \mathrm{7.1}$. Tested with Nessler reagent after 5 days.

16. Urea breakdown by Christensen's (1946) method, in cotton-wool-plugged tubes, read over 7 days.

17. Egg-yolk reaction, tested as recommended by Willis (1960) after 6 days. 
18. Tributyrin hydrolysis, tested by clearing within 7 days of Oxoid glycerol tributyrate $(1 \%, w / v)$ agar.

19. Utilization of organic acids as sole carbon sources. Medium: Koser salt solution plus $1.5 \%(\mathrm{w} / \mathrm{v})$ agar and $0.008 \%$ bromothymol blue, $\mathrm{pH} 6.8$. Acids added as sodium salts to give $\mathbf{0 . 2 5} \%(\mathrm{w} / \mathrm{v})$ final concentration. Succinic, malic, acetic, citric, lactic and oxalic acids tested. Tested on slopes, read up to 7 days.

20. Acid production from ethanol, test of Shimwell et al. (1960).

21. Oxidation of calcium lactate to carbonate, test of Shimwell et al. (1960).

22. Catalase production, as R.W.A.P.

23. Oxidase production, as R.W.A.P.

24. Cytochrome oxidase production, as R.W.A.P.

25. Phosphatase production, tested upon nutrient agar containing $0.006 \%(\mathrm{w} / \mathrm{v})$ phenolphthalein phosphate, exposed after 5 days to vapour from 0.880 ammonia solution.

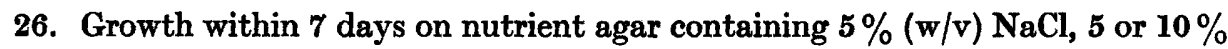
$(\mathrm{w} / \mathrm{v})$ sodium taurocholate; growth and reduction with 0.2 or $1 \%(\mathrm{w} / \mathrm{v})$ triphenyl tetrazolium chloride (т.T.c.) (Meitert, Meitert \& Horodniceanu, 1960).

27. Growth and characteristics upon MacConkey, Wilson \& Blair, Dieudonné and deoxycholate-citrate agars (Mackie \& McCartney, 1953), over 7 days.

28. Growth on nutrient agar under strict anaerobiosis, 7 days.

29. Growth in nutrient broth at $4^{\circ}$ (14 days), $14^{\circ}, 25^{\circ}, 30^{\circ}, 44^{\circ}$ (7 days).

30. Growth from initial pH 4.5, test of Shimwell et al. (1960).

31. Pigment production. Routine observation of all cultures in daylight; fluorescence under u.v. of growth upon the glucose-calcium carbonate medium of R.W.A.P.

32. Resistance to antibacterial agents. Tested using Evans 'Sentest' or Mast disks on surface seeded nutrient agar. Antibiotics: penicillin, 1 and 2.5 i.u.; streptomycin, 20 and $80 \mu \mathrm{g}$.; chloramphenicol, 40 and $100 \mu \mathrm{g}$; ; Aureomycin, 10 and $100 \mu \mathrm{g}$.; Terramycin, 10, 25 and $100 \mu \mathrm{g}$.; erythromycin, 1 and $10 \mu \mathrm{g}$.; tetracycline, $100 \mu \mathrm{g}$.; neomycin, $100 \mu \mathrm{g}$.; bacitracin, 5.5 units; novobiocin, 5 and $10 \mu \mathrm{g}$.; oleandomycin, 5 and $20 \mu \mathrm{g}$. Also tested $\mathrm{O} / 129$ (see R.W.A.P.) using an aqueous suspension ( $c$. $50 \mathrm{mg}$. in $20 \mathrm{ml}$.) and agar well technique. (Note: a saturated aqueous solution of 0/129 proved non-inhibitory against Vibrio comma in preliminary tests.)

\section{RESULTS}

Tables 1 (R.W.A.P.) and 2 (G.H.G.D.) show the results obtained by the two authors and the classification of strains into three groups on the evidence of these results. The overall characters of these three groups are compared in Table 3.

Morphological details are not readily presentable in tables and we therefore include here an account of our observations. The six strains of Vibrio comma used by G.H.G.D., and strains 4693 (V. comma), 5395 ((V. eltor), 8563 (V. proteus), 8042, 4711, 4715 and 4716 studied by R.W.A.P. all exhibited pleomorphism. Straight and curved short rods, S-forms, spirals, undulating filaments and spheroplasts (Pitzurra \& Szybalski, 1959) were regularly seen. This variety of forms has been reported before in studies upon $V$. comma (Koch, 1886; Henrici, 1925). Plate 1, figs. 1 and 7 , illustrates some of these forms. $V$. paracholerae (NCTC 30) did not 
Table 1. Results of R.W.A.P.

\begin{tabular}{|c|c|c|c|c|c|c|c|c|c|c|c|c|c|c|}
\hline \multirow[b]{2}{*}{$\begin{array}{l}\text { Strain } \\
\text { Flagellation }\end{array}$} & \multicolumn{8}{|c|}{ Vibrio spp. } & \multicolumn{2}{|c|}{$\begin{array}{c}\text { Pseudo- } \\
\text { monas }\end{array}$} & \multicolumn{4}{|c|}{ Comamonas spp. } \\
\hline & $\begin{array}{l}\mathbf{4 6 9 3} \\
1 \mathrm{~L}\end{array}$ & $\begin{array}{c}4711 \\
1 L\end{array}$ & $\begin{array}{l}4715 \\
1 \mathrm{~L}\end{array}$ & $\begin{array}{l}4716 \\
1 \mathrm{~L}\end{array}$ & $\begin{array}{c}8042 \\
1 \mathrm{~L}\end{array}$ & $\begin{array}{l}5395 \\
1 \mathrm{~L}\end{array}$ & $\begin{array}{l}8563 \\
1 L\end{array}$ & $\begin{array}{l}\mathbf{3 0} \\
\mathbf{1 L}\end{array}$ & $\begin{array}{c}\mathbf{8 1 0 4} \\
\mathbf{M}\end{array}$ & $\begin{array}{l}2581 \\
\text { ML }\end{array}$ & $\begin{array}{l}2582 \\
\text { ML }\end{array}$ & $\underset{\mathbf{M}}{1937}$ & 9239 & 8250 \\
\hline \multicolumn{15}{|l|}{$\begin{array}{l}\text { Acid production and } \\
\text { utilization of: }\end{array}$} \\
\hline Arabinose & - & - & - & - & - & - & - & - & $+U$ & - & - & - & - & - \\
\hline Gluc & + & + & + & + & + & + & + & + & $+U$ & - & - & - & - & - \\
\hline Fructose & + & + & + & + & + & + & + & + & - & - & - & - & - & - \\
\hline Mar & + & - & + & + & + & + & + & + & $+U$ & - & - & - & - & - \\
\hline $\begin{array}{l}\mathbf{G a} \\
\mathbf{M g}\end{array}$ & \pm & + & + & \pm & + & + & \pm & + & $+U$ & - & - & - & - & - \\
\hline $\begin{array}{l}\text { ManI } \\
\text { Sorbi }\end{array}$ & $\underline{+}$ & $\stackrel{+}{-}$ & $\stackrel{+}{-}$ & \pm & \pm & \pm & \pm & $\begin{array}{l}+ \\
+\end{array}$ & $\bar{z}$ & $\bar{z}$ & $\bar{z}$ & $\bar{z}$ & $\overline{-}$ & \\
\hline Sucro & + & + & + & + & + & + & \pm & - & - & - & - & - & $=$ & $z$ \\
\hline & \pm & \pm & \pm & \pm & + & \pm & \pm & \pm & - & - & - & - & - & - \\
\hline Malt & + & + & + & + & + & + & $\bar{t}$ & $\bar{t}$ & - & - & - & - & - & - \\
\hline $\begin{array}{l}\text { Salicin } \\
\text { Iugh \& Lei }\end{array}$ & $\overline{\mathbf{F}}$ & $\bar{\pi}$ & $\bar{\pi}$ & $\bar{\pi}$ & + & $\bar{x}$ & \pm & $\bar{m}$ & $\overline{0}$ & $\overline{1}$ & $\overline{11}$ & $\overline{1}$ & $\overline{1}$ & $\overline{1}$ \\
\hline $\begin{array}{l}\text { Hugh \& Leifson test } \\
\text { Gluconate test (Hayn }\end{array}$ & $\underline{\mathbf{F}}$ & $\mathbf{F}$ & $\mathbf{F}$ & F & $\mathbf{F}$ & & $\mathbf{F}$ & $\mathbf{F}$ & 0 & Al. & Al. & Al. & Al. & Al. \\
\hline cet & - & + & $t$ & $\begin{array}{l}+ \\
+\end{array}$ & $\overline{+}$ & $\bar{t}$ & $\overline{-}$ & $\stackrel{+}{-}$ & $z$ & $\bar{z}$ & $\overline{-}$ & $\overline{-}$ & $=$ & $z$ \\
\hline & - & - & - & - & + & + & - & - & $\bar{z}$ & $\overline{-}$ & $=$ & $=$ & $\overline{-}$ & $\bar{z}$ \\
\hline tarc & + & + & + & + & + & + & + & + & - & - & - & - & - & $\overline{-}$ \\
\hline & + & + & + & + & + & + & - & + & - & - & - & + & + & - \\
\hline & + & + & + & - & + & - & - & + & - & - & - & - & - & - \\
\hline $\begin{array}{l}\text { Indole production } \\
\text { Utilization of: }\end{array}$ & + & + & + & + & + & - & + & + & - & - & 一 & - & - & - \\
\hline Try & - & - & - & - & - & - & - & - & $+B$ & - & - & - & - & + \\
\hline & - & - & - & & & - & - & - & + & - & - & 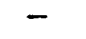 & - & - \\
\hline & - & - & - & - & - & - & - & - & - & - & - & - & - & + \\
\hline Benz & - & - & - & 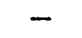 & . & - & - & - & + & - & & - & 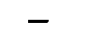 & + \\
\hline Cate & - & - & - & - & - & - & - & - & - & - & - & - & - & + \\
\hline ssolution & + & + & - & - & - & - & - & - & + & - & + & + & $+B$ & + \\
\hline anine (Shaw \& & - & - & - & - & 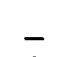 & - & - & - & - & - & - & - & - & + \\
\hline drolysis & + & + & + & + & + & + & + & + & + & - & - & - & + & - \\
\hline & \pm & + & + & - & \pm & + & \pm & \pm & $=$ & - & - & - & - & - \\
\hline & + & $t$ & \pm & \pm & \pm & \pm & \pm & +1 & $\bar{z}$ & $\bar{z}$ & $\overline{-}$ & $\bar{t}$ & $=$ & $\bar{z}$ \\
\hline $\begin{array}{l}\mathbf{H}_{2} \mathrm{St} \\
\text { Urea }\end{array}$ & \pm & \pm & $=$ & $\underline{I}$ & \pm & $=$ & $=$ & $\underline{I}$ & \pm & $=$ & $\bar{t}$ & $\frac{1}{t}$ & $\overline{-}$ & - \\
\hline $\begin{array}{r}\text { Utili } \\
\text { Su }\end{array}$ & & & & & & & & & & & & & & \\
\hline & + & + & & & + & & & - & + & - & - & - & - & + \\
\hline & $\begin{array}{l}+ \\
t\end{array}$ & & - & & - & & & & 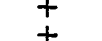 & $=$ & $=$ & $\bar{z}$ & - & + \\
\hline & - & $t$ & 7 & & $t$ & & & & + & $\overline{-}$ & - & $=$ & - & $\begin{array}{l}+ \\
+\end{array}$ \\
\hline & + & - & & & & & & & $r$ & - & - & - & - & - \\
\hline & + & & -1 & & & & & & & - & & & & - \\
\hline $\mathbf{M a}$ & 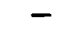 & 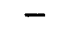 & - & & 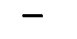 & 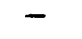 & 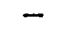 & - & + & - & 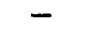 & - & 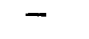 & - \\
\hline & - & - & - & - & - & - & - & - & + & - & - & - & - & + \\
\hline nd acid & - & - & - & - & - & - & - & - & $\mathbf{U}$ & - & & - & - & \\
\hline $\begin{array}{l}\text { fro } \\
\text { Cat: }\end{array}$ & \pm & - & \pm & & - & 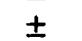 & 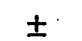 & & + & + & $\overline{ \pm}$ & \pm & - & $\begin{array}{l}\mathrm{UA} \\
+\end{array}$ \\
\hline $\mathbf{K}$ & $\bar{\mp}$ & 7 & $\mp$ & & 1 & t & - & & + & - & - & $\doteq$ & + & + \\
\hline & \pm & \pm & + & & & - & 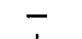 & & \pm & \pm & \pm & - & - & - \\
\hline & & & & & & & & & & & & - & - & - \\
\hline & + & + & -1 & 1 & + & 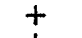 & & & . & + & - & + & & - \\
\hline & + & & + & & 1 & & d & & - & + & & - & & - \\
\hline $\mathrm{ald}_{2}$ & + & & + & & + & + & + & & + & - & $\cdot$ & - & 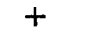 & - \\
\hline $\mathrm{TaCl}$ & & & & & & & & & 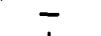 & - & - & - & - & - \\
\hline $\mathbf{M}$ & + & - & $t$ & $t$ & + & $t$ & + & & + & - & + & 1 & & + \\
\hline & & & - & & & & & & - & - & & & & - \\
\hline & & 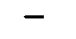 & & & 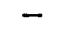 & 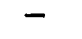 & 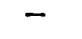 & & + & - & 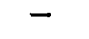 & - & 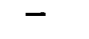 & - \\
\hline & - & 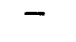 & - & 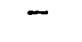 & - & - & - & - & + & - & - & - & - & - \\
\hline $\mathbf{P e}$ & + & - & - & \pm & - & \pm & \pm & - & - & - & - & - & - & - \\
\hline $\begin{array}{l}\text { Streptc } \\
\mathbf{0} / \mathbf{1 2 9}\end{array}$ & + & & + & $\stackrel{+}{+}$ & + & + & $\stackrel{+}{+}$ & \pm & \pm & \pm & \pm & \pm & $\overline{-}$ & \pm \\
\hline
\end{tabular}

Key, see p. 119. 
Table 2. Results of G.H.G.D.

\begin{tabular}{|c|c|c|c|c|c|c|c|c|c|c|c|}
\hline \multirow[b]{2}{*}{ Strain } & \multicolumn{6}{|c|}{ Vibrio spp. } & \multirow{2}{*}{$\begin{array}{c}\text { Pseudo- } \\
\text { monas } \\
\text { spp. } \\
\mathbf{8 1 9 4}\end{array}$} & \multicolumn{4}{|c|}{ Comamonas spp. } \\
\hline & 4693 & 6585 & 7270 & 7254 & 8021 & 8367 & & 2581 & 2582 & 8193 & 8250 \\
\hline Flagellation & 1L & 1L & IL & 1L & 1L & 1L & $\mathbf{M}$ & $\mathbf{M}$ & $\mathbf{M}$ & $\mathbf{M}$ & - \\
\hline \multicolumn{12}{|l|}{ Acid from: } \\
\hline Arabinose & - & - & - & - & - & - & 7 & 10 & - & - & - \\
\hline Xylose & - & - & - & - & - & - & 8 & - & - & - & - \\
\hline Glucose & $\mathbf{3}$ & $\mathbf{3}$ & $\mathbf{3}$ & $\mathbf{3}$ & 8 & $\mathbf{3}$ & $\mathbf{8}$ & 12 & - & - & - \\
\hline Fructose & $\mathbf{8}$ & $\mathbf{3}$ & $\mathbf{3}$ & $\mathbf{3}$ & $\mathbf{3}$ & $\mathbf{3}$ & 10 & 10 & - & - & - \\
\hline Mannose & $\mathbf{3}$ & $\mathbf{3}$ & $\mathbf{3}$ & $\mathbf{3}$ & $\mathbf{3}$ & $\mathbf{3}$ & 8 & 14 & - & - & - \\
\hline Galactose & - & $\mathbf{3}$ & $\mathbf{3}$ & $\mathbf{3}$ & $\mathbf{3}$ & $\mathbf{3}$ & 8 & 14 & - & - & - \\
\hline Rhamnose & - & - & - & - & - & - & - & $\boldsymbol{\gamma}$ & - & - & - \\
\hline Mannitol & 7 & $\mathbf{3}$ & $\mathbf{3}$ & $\mathbf{3}$ & $\mathbf{3}$ & $\mathbf{3}$ & 7 & 10 & - & - & - \\
\hline Inositol & - & - & - & - & - & - & 7 & - & - & - & - \\
\hline Sucrose & 8 & $\mathbf{3}$ & $\mathbf{3}$ & $\mathbf{3}$ & $\mathbf{3}$ & $\mathbf{3}$ & 5 & 7 & - & - & - \\
\hline Maltose & 8 & $\mathbf{3}$ & $\mathbf{3}$ & $\mathbf{3}$ & 3 & $\mathbf{3}$ & - & 14 & - & - & - \\
\hline Lactose & - & 7 & 12 & 7 & 12 & - & - & 12 & - & - & - \\
\hline Melibiose & - & - & - & - & - & - & $\mathbf{3}$ & 12 & - & - & - \\
\hline Dextrin & 8 & $\mathbf{3}$ & $\mathbf{3}$ & $\mathbf{3}$ & $\mathbf{3}$ & $\mathbf{8}$ & - & 10 & - & - & - \\
\hline Glycogen & 8 & $\mathbf{3}$ & $\mathbf{3}$ & $\mathbf{3}$ & $\mathbf{8}$ & $\mathbf{3}$ & - & - & - & - & - \\
\hline Salicin & - & - & - & - & - & - & - & 12 & - & - & - \\
\hline Hugh \& Leifson test & $\mathbf{F}$ & $\mathbf{F}$ & $\mathbf{F}$ & $\mathbf{F}$ & $\mathbf{F}$ & $\mathbf{F}$ & $\mathbf{o}$ & $0 \pm$ & - & - & - \\
\hline Methyl-red test & + & + & + & + & + & + & - & $=$ & - & - & - \\
\hline Acetoin & - & - & \pm & - & - & - & - & - & - & - & - \\
\hline pH $1 \%$ glucose & $5 \cdot 1$ & $5 \cdot 1$ & $5 \cdot 1$ & $6 \cdot 1$ & $5 \cdot 1$ & $4 \cdot 5$ & $6 \cdot 1$ & 6.7 & 6.7 & $7 \cdot 1$ & $7 \cdot 1$ \\
\hline Starch hydrolysis & + & + & + & + & + & + & - & \pm & - & - & - \\
\hline Aesculin hydrolysis & - & - & - & - & - & - & - & $\bar{t}$ & - & - & - \\
\hline Nitrate reduction & + & + & + & + & + & + & + & + & + & - & - \\
\hline Cholera-red test & + & + & + & + & + & + & - & - & - & - & - \\
\hline Indole & + & + & + & + & + & + & - & - & - & - & - \\
\hline Tyrosine dissolution & \pm & - & \pm & - & - & - & + & - & + & + & + \\
\hline Gelatin hydrolysis & $\bar{t}$ & + & $\bar{t}$ & + & + & + & + & - & - & - & - \\
\hline Serum hydrolysis & - & + & + & + & + & + & + & - & - & - & - \\
\hline Casein hydrolysis & + & + & + & + & + & + & - & \pm & - & - & - \\
\hline Lysine decarboxylase & + & + & + & + & + & + & - & $=$ & - & - & - \\
\hline Hide-powder lysis & + & + & + & + & + & + & - & - & - & - & - \\
\hline $\mathrm{H}_{2} \mathrm{~S}$ cysteine & + & + & + & + & + & + & \pm & \pm & \pm & \pm & \pm \\
\hline $\mathrm{H}_{2} \mathrm{~S}$ thiosulphate & + & + & + & + & + & + & $=$ & \pm & \pm & \pm & $=$ \\
\hline $\mathrm{NH}_{3}$ from arginine & - & - & - & - & - & - & + & $=$ & $=$ & $=$ & - \\
\hline Urease & - & - & - & - & - & - & + & - & + & + & - \\
\hline Egg yolk reaction & $\mathbf{L i}$ & $\mathbf{L i}$ & $\mathbf{L i}$ & $\mathbf{L i}$ & $\mathbf{L i}$ & $\mathbf{L i}$ & $\mathbf{L i}$ & - & - & - & $\mathbf{L i} \pm$ \\
\hline Tributyrin & NG & NG & NG & NG & NG & NG & + & + & + & + & $\bar{T}$ \\
\hline \multicolumn{12}{|l|}{ Utilization of } \\
\hline Malic & + & + & + & + & + & + & + & - & + & + & + \\
\hline Acetic & + & + & + & + & + & + & + & - & + & + & + \\
\hline Lactic & + & + & + & + & + & + & + & - & + & + & + \\
\hline Oxalic & - & - & - & - & - & - & - & - & - & + & - \\
\hline Acid from ethanol & - & - & - & - & - & - & - & - & - & - & \pm \\
\hline Lactate oxidation & - & - & - & - & - & - & - & - & - & - & $\bar{t}$ \\
\hline Catalase & \pm & \pm & \pm & \pm & \pm & \pm & + & + & + & + & + \\
\hline Kovacs oxidase & $\bar{t}$ & $\bar{t}$ & $\bar{t}$ & $\bar{t}$ & + & $t$ & + & - & + & + & - \\
\hline Cytochrome oxidase & + & + & + & + & + & + & - & - & \pm & - & - \\
\hline Phosphatase & - & - & - & - & - & - & + & - & $=$ & - & \pm \\
\hline $5 \% \mathrm{NaCl}$ tolerance & + & \pm & - & + & - & + & \pm & + & - & - & \pm \\
\hline $5 \%$ Bile tolerance & \pm & $t$ & + & + & + & + & $\bar{t}$ & - & + & \pm & t \\
\hline $10 \%$ Bile tolerance & \pm & - & + & + & + & + & + & - & - & $=$ & + \\
\hline \multicolumn{12}{|c|}{ Key, see p. 119.} \\
\hline
\end{tabular}


Table 2 (cont.)

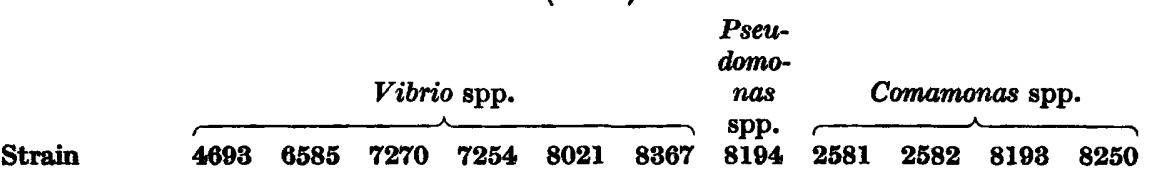

\begin{tabular}{|c|c|c|c|c|c|c|c|c|c|c|c|}
\hline $0.2 \%$ T.T.C. tolerance & - & - & + & - & + & - & + & - & + & + & + \\
\hline $1 \%$ T.T.C. tolerance & - & - & - & - & - & - & + & - & - & - & - \\
\hline MacConkey & + & + & + & + & + & + & + & - & + & + & + \\
\hline Wilson and Blair & - & + & + & + & + & + & + & - & $+\mathbf{B}$ & + & $+B$ \\
\hline Dieudonné & + & + & + & + & + & + & \pm & - & - & - & - \\
\hline Deoxycholate-citrate & - & + & + & + & + & + & $\bar{t}$ & - & - & - & - \\
\hline Anaerobic growth & \pm & \pm & \pm & \pm & \pm & \pm & - & - & - & - & - \\
\hline Growth at $4^{\circ}$ & $=$ & $\overline{-}$ & $\bar{z}+x+1+x$ & $\bar{z}$ & $\overline{-}$ & $\overline{-}$ & + & \pm & - & - & \pm \\
\hline Growth at $14^{\circ}$ & + & + & + & + & + & + & + & \pm & + & \pm & $\bar{t}$ \\
\hline Growth at pH 4.5 & - & - & - & - & - & - & + & $=$ & + & $\bar{t}$ & + \\
\hline Pigment daylight & - & - & - & - & - & - & YG & $\mathbf{Y}$ & - & - & - \\
\hline Fluorescence, u.v. & - & - & - & - & - & - & + & - & - & - & - \\
\hline Susceptible to & & & & & & & & & & & \\
\hline $\begin{array}{l}\text { Chloramphenicol } \\
100\end{array}$ & + & + & + & + & + & + & \pm & + & + & \pm & + \\
\hline Chloramphenicol 40 & + & + & + & + & + & + & \pm & - & + & - & + \\
\hline Terramycin 10 & + & + & + & + & + & + & t & + & + & \pm & + \\
\hline Tetracycline 100 & + & + & + & \pm & + & + & + & + & + & $\bar{t}$ & \pm \\
\hline Aureomycin 100 & + & + & + & + & + & + & \pm & + & + & + & \pm \\
\hline Aureomycin 10 & + & + & + & + & + & + & $=$ & + & + & + & $\overline{-}$ \\
\hline Streptomycin 80 & + & + & + & + & + & + & + & + & + & - & + \\
\hline Streptomycin 20 & + & + & + & + & + & + & + & + & + & - & + \\
\hline Neomycin 100 & + & + & + & + & + & + & + & + & + & - & - \\
\hline Erythromycin 10 & + & + & + & + & + & + & - & + & - & - & - \\
\hline Erythromycin 1 & + & + & + & - & + & \pm & - & \pm & - & - & _ \\
\hline Novobiocin 10 & + & + & + & + & + & $\bar{t}$ & - & $\bar{t}$ & - & - & - \\
\hline Novobiocin 5 & + & + & + & + & + & + & - & - & - & - & - \\
\hline Oleandomycin 20 & + & + & + & - & + & \pm & - & + & - & - & - \\
\hline $\mathbf{0} / \mathbf{1 2 9}$ & \pm & \pm & + & - & \pm & \pm & - & - & - & - & - \\
\hline
\end{tabular}

show the same degree of pleomorphism, only straight and curved rods and spheroplasts were seen (Pl. 1, fig. 2). All these strains exhibited single polar flagella upon the short cell forms and often had a flagellum at both poles of the longer forms, some of which appeared to be dividing (Pl. 1, fig. 1). Spheroplasts commonly retained flagella but motility of spheroplasts was never observed in living material (cf. Jeynes, 1961).

Strain 8194 (Vibrio cuneatus) consisted of robust, round-ended rods which were usually curved (Pl. 1, fig. 4). One or more polar flagella were seen (1-10, R.W.A.P.). No pleomorphism other than variation in cell length was observed and this may correlate with observed colonial variations between smooth soft and rough hard forms. The tapering cell forms described by Gray \& Thornton (1928) were not seen.

Strains 2581 (Vibrio cyclosites) and 2582 ( $V$. neocistes) were observed by R.W.A.P. as fairly robust, straight rods with round ends, usually bearing 2-6 flagella at one pole and one at the other (Pl. 1, fig. 3). Leifson (1960) has illustrated a very similar form (Leifson, fig. $16 d$ ) showing division of the organism. Our figure does not show division in progress. G.H.G.D. observed lophotrichous but not bipolar, flagellation in strain 2518. Loss of motility appeared to occur readily in this strain and 
coccoid and swollen forms were sometimes seen. Strain 2582 was similar in flagellation to 2581, and regularly motile. Filamentous forms that divided by constriction (Bisset, 1952), and appeared as chains of fusiform cells were observed in strain 2582.

Strains 8193 (G.H.G.D.) and 1937 (R.W.A.P.) (Vibrio percolans) were observed by both authors to consist of robust, straight rods with round ends and 1-5 flagella at one pole (Pl. 1, fig. 5). Filamentous forms showing constrictions were common, cf. Leifson (1960, fig. 16c), and strain 2582 above. Similar tendencies to filamentous

Table 3. Comparison of certain results from R.W.A.P. and G.H.G.D. for the groups indicated in Tables 1 and 2

\begin{tabular}{|c|c|c|c|c|c|c|}
\hline \multirow{2}{*}{$\begin{array}{c}\text { Group } \\
\text { Author and number } \\
\text { of strains }\end{array}$} & \multicolumn{2}{|c|}{ Vibrio } & \multicolumn{2}{|c|}{$\begin{array}{l}P \text {. fluorescens } \\
\text { (8194) }\end{array}$} & \multicolumn{2}{|c|}{ Comamonas } \\
\hline & $\underset{(8)}{\text { R.W.A.P. }}$ & $\underset{(6)}{\text { G.H.G.D. }}$ & $\begin{array}{l}\text { R.W.A.P. } \\
\text { (1) }\end{array}$ & $\underset{\text { (1) }}{\text { G.H.G.D. }}$ & $\underset{\text { (5) }}{\text { R.W.P. }}$ & $\begin{array}{c}\text { G.H.G.D. } \\
(4)\end{array}$ \\
\hline $\begin{array}{l}\text { Flagellation } \\
\text { Acid from }\end{array}$ & IL & $1 L$ & $\mathbf{M}$ & $\mathbf{M}$ & $1, M$ or $M L$ & $\mathbf{3} / \mathbf{4} \mathrm{M}$ \\
\hline Arabinose & - & - & $+U$ & + & - & $1 / 4 \pm$ \\
\hline Xylose & NT & - & NT & + & NT & - \\
\hline Glucose & + & + & $+\mathrm{U}$ & + & - & $1 / 4 \pm$ \\
\hline Fructose & + & + & - & \pm & - & $1 / 4 \pm$ \\
\hline Mannose & $7 / 8$ & + & $+U$ & + & - & $1 / 4 \pm$ \\
\hline Galactose & tor \pm & $5 / 6$ & $+U$ & + & - & $1 / 4 \pm$ \\
\hline Rhamnose & NT & - & NT & - & NT & $1 / 4 \pm$ \\
\hline Mannitol & + & + & - & \pm & - & $1 / 4 \pm$ \\
\hline Inositol & NT & - & NT & \pm & NT & - \\
\hline Sorbitol & $1 / 8$ & - & - & $=$ & - & - \\
\hline Sucrose & $7 / 8$ & + & - & + & - & $1 / 4 \pm$ \\
\hline Lactose & \pm & $4 / 6 \pm$ & - & - & - & $1 / 4 \pm$ \\
\hline Maltose & $\bar{t}$ & + & - & - & - & $\mathbf{1 / 4 \pm}$ \\
\hline Melibiose & $\mathbf{N T}$ & - & NT & + & NT & $1 / 4 \pm$ \\
\hline Dextrin & NT & + & $\mathbf{N T}$ & - & NT & $1 / 4 \pm$ \\
\hline Glycogen & NT & + & NT & - & NT & - \\
\hline Salicin & $2 / 8$ & - & - & - & - & $1 / 4 \pm$ \\
\hline Hugh \& Leifson test & $\mathbf{F}$ & $\mathbf{F}$ & $\mathbf{0}$ & 0 & $\mathrm{Al}$ & $1 / 4 \pm 0$ \\
\hline Methyl-red test & $2 / 8$ & + & - & - & - & - \\
\hline Acetoin & $5 / 8$ & $1 / 6$ & - & - & - & - \\
\hline pH $1 \%$ glucose & NT & below 6 & NT & $7 \cdot 1$ & NT & c. 7 \\
\hline Starch hydrolysis & + & + & - & - & - & $1 / 4 \pm$ \\
\hline Aesculin hydrolysis & N1' & - & NT & - & NT & $1 / 4 \pm$ \\
\hline Nitrate reduction & $7 / 8$ & + & - & + & $2 / 5$ & $2 / 4$ \\
\hline Cholera-red test & $5 / 8$ & + & - & - & - & - \\
\hline Indole & $r / 8$ & + & - & - & - & - \\
\hline Tyrosine dissoluton & $2 / 8$ & $2 / 6 \pm$ & + & + & $4 / 5$ & $3 / 4$ \\
\hline Gelatin hydrolysis & + & + & + & + & $1 / 5$ & - \\
\hline Serum hydrolysis & $7 / 8 \pm$ or + & $5 / 6$ & + & + & $1 / 5$ & - \\
\hline Casein hydrolysis & + & + & - & - & - & $1 / 4 \pm$ \\
\hline Lysine decarboxylase & NT & + & NT & - & NT & - \\
\hline Hide-powder lysis & NT & + & NT & - & NT & - \\
\hline $\mathrm{H}_{2} \mathrm{~S}$ cysteine & NT & + & NT & \pm & NT & \pm \\
\hline $\mathrm{H}_{2} \mathrm{~S}$ thiosulphate & $\mathbf{N T}$ & + & NT & $=$ & NT & $\overline{3} / 4 \pm$ \\
\hline $\mathbf{H}_{8} \mathbf{S}$ peptone & $5 / 8 \pm$ & NT & - & NT & $1 / 5 \pm$ & NT \\
\hline $\mathrm{NH}_{8}$ from arginine & NT & - & $\mathbf{N T}$ & + & $\mathbf{N T}{ }^{-}$ & - \\
\hline Urease & - & - & \pm & + & $2 / 5$ & $2 / 4$ \\
\hline Tributyrin $0.2 \%$ & + & NT & $\bar{t}$ & NT & + & NT \\
\hline ibutyrin $1 \%$ & $\mathbf{N T}$ & NG & NT & + & NT & + \\
\hline Ggg-yolk reaction & NT & $\mathbf{L} \mathbf{i}$ & NT & $\mathbf{L i}$ & NT & $1 / 4 \mathrm{Li} \pm$ \\
\hline
\end{tabular}

Key, see p. 118. 
Table 3 (cont.)

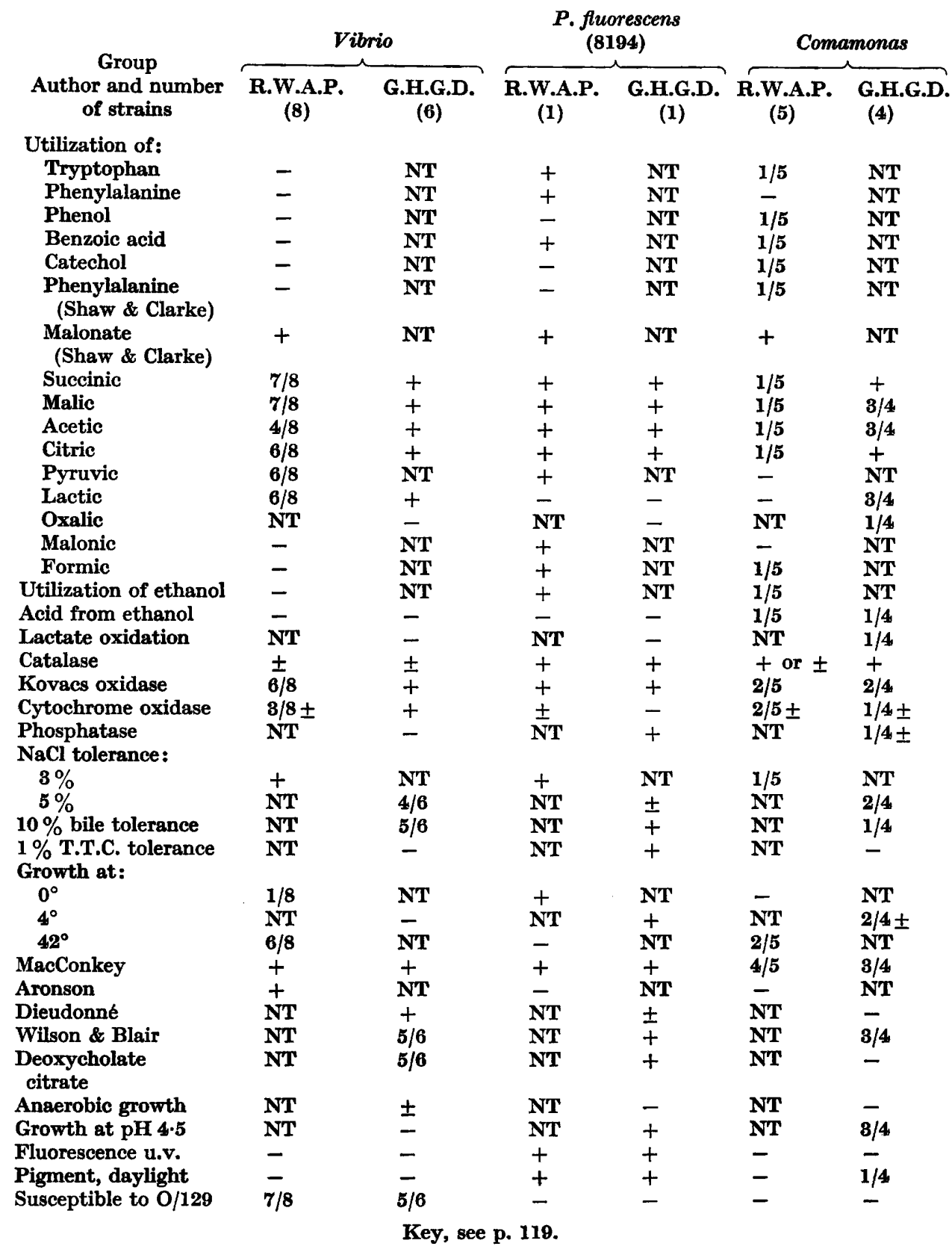

growth were observed by R.W.A.P. in certain freshly isolated water bacteria classified as Comamonas sp. (Park, 1961 a). Variation from polar to peritrichous flagellation as described by Leifson \& Hugh (1953) for this organism was not observed, although in a preparation stained by Leifson's (1960) method, many cells 
exhibited flagellation similar to that described as 'degenerate peritrichous' by Conn \& Wolfe (1938), or 'subpolar' by Leifson (1960). When originally isolated by Mudd \& Warren (1923) this organism was found to display a range of morphological forms including what may have been spheroplasts.

Strain 8250 (Vibrio 01) had a regular cell form of single and paired, short, thick, straight rods. They appeared to be square-ended in cell-wall stained preparations. R.W.A.P. observed a few motile organisms in peptone water cultures and found occasional organisms bearing one or two flagella at one pole by electron microscopy. Motility was presumably a character of this strain when originally isolated (Happold \& Key, 1932) but it appears to be easily lost. No motility was detected by G.H.G.D. and no flagella demonstrated.

Strain 9239 (R.W.A.P.) (Vibrio alcaligenes) consisted of round-ended straight rods having one or two flagella at one pole. No other forms were seen (Pl. 1, fig. 6).

Table 4. Comparison of Vibrio, Aeromonas, Pseudomonas and Comamonas reactions in possible diagnostic tests

\begin{tabular}{|c|c|c|c|c|}
\hline & Vibrio & Aeromonas & Pseudomonas & Comamonas \\
\hline Spheroplasts regularly formed & + & - & - & - \\
\hline Pleomorphic & + & - & - & - \\
\hline Single polar flagellum & + & V & $\mathbf{V}$ & $\mathbf{V}$ \\
\hline Fluoresce under u.v. & - & - & + & - \\
\hline Growth at $\mathrm{pH} 9$ & + & $\mathbf{V}$ & $\mathbf{V}$ & $\mathbf{V}$ \\
\hline Susceptible to $0 / 129$ & $+(V)$ & $-?$ & - & - \\
\hline Hugh \& Leifson test & Ferment & Ferment & Oxidize & $\begin{array}{l}\text { Alkaline } \\
\text { or Nil }\end{array}$ \\
\hline Gas from glucose & - & $+(\mathbf{V})$ & - & - \\
\hline Cholera-red test & $\mathbf{V}$ & - & - & - \\
\hline
\end{tabular}

Key: $+=$ positive; $-=$ negative $\mathbf{V}=$ some strains positive; $+(\mathrm{V})=$ most strains positive; $?=$ see Rhodes (1959) and text.

Note. This table is based on our own results, see Park (1961 a), and those of previous workers.

Detailed comparisons of our other results can readily be made from the tables we have given. One or two features of these results will serve as examples.

Differences in the results of Kovacs oxidase test and the cytochrome oxidase test in the two studies probably reflect a lack of definition in the execution and reading of these tests. One of us (G.H.G.D.) found some variation in results of the cytochrome oxidase test when the strains were tested in various ways, e.g. young and old, broth and agar cultures. Agar cultures tested by the filter-paper technique gave the clearest results. On the other hand, differences in the results for tributyrin attack are explained by the use of different tributyrin concentrations by the two authors (see Methods). It is interesting to note that all six strains of Vibrio comma tested by G.H.G.D. failed to grow in 7 days on $1 \%(w / v)$ tributyrate agar (cf. Collins \& Hammer, 1934).

Good general agreement in carbohydrate metabolism tests is noticeable. The detection of weak oxidation of glucose by strain 2581 (G.H.G.D.) and late attack of various sugars by the same strain may be explained by the absence of peptone from the basal medium used (cf. Liu, 1952). Ammonia production from peptone or arginine was not detected for this strain (G.H.G.D.), but an alkaline reaction was recorded in the standard Hugh \& Leifson test(R.W.A.P.). The strain grew in peptone 
water which indicates that peptone was attacked, and breakdown products could have masked weak acid production in the tests of R.W.A.P. This does not. however, explain the fact that R.W.A.P. obtained exactly similar results in Simon medium (see Methods). It is possible that the yeast extract used in the medium of G.H.G.D. may have given rise to false late positive results, and it is also possible that differences in the initial $\mathrm{pH}$ value and $\mathrm{pH}$ indicators employed may have contributed to the different results obtained. Strains 2581 and 2582 were originally described as producing acid from glucose (Gray \& Thornton, 1928). R.W.A.P. found that strain 9239 produced an acid reaction in peptone water and also in all the carbohydratepeptone water media except those containing sucrose or maltose, which became very alkaline. These findings emphasize the need for controls when peptone water is used as a base for carbohydrate breakdown tests (cf. also Orcutt \& Nutting, 1942).

The attack on hide powder by Vibrio comma confirmed to some extent the report by Narayanan \& Menon (1952) of collagenase activity in this organism. This character is fairly common in other Gram-negative polarly flagellate bacteria.

In our results the egg-yolk reaction of Vibrio comma was interpreted as due to lipolysis. The 'pearly layer' effect of Willis (1960) was evident, and zones of what appeared to be a crystalline precipitate which reacted with copper sulphate were produced. Felsenfeld (1944) reported lecithinase activity in $V$. comma.

The test for lysine-decarboxylase activity yielded clear results and may be of taxonomic value (Szturm-Rubinsten, Piéchaud \& Piéchaud, 1960). Thibauit \& Le Minor (1957) reported the use of this test for the differentiation of enterobacteria.

Preliminary analyses of the cell-wall amino-acid components of strains 4693, 8250 and 8194 by the technique of Davis \& Freer (1960) indicated gross similarity between these strains and various other Gram-negative bacteria (e.g. Neisseria sp., coliforms, etc.). Qualitative differentiation was not possible and all strains so far examined yielded typical Gram-negative, i.e. complex, amino acid patterns.

\section{DISCUSSION}

In this study we have applied a large number and variety of simple tests to a small number of bacterial strains representing all but two (Vibrio fetus, see Park, $1961 b$, and $V$. metschnikovii) of the so-called vibrios available in the National Collection of Industrial Bacteria and National Collection of Type Cultures. Although the results obtained by the two authors differ in details, the classification of strains derived from these two independent studies is the same. Tables 1 and 2 show how the strains were analysed into groups; the first group in each table represents what we consider to be true members of the genus Vibrio, the second (strain 8194) exhibits characters typical of Pseudomonas fuorescens, while the third group is comprised of strains that we regard as representatives of the genus named Lophomonas by Galarneault \& Leifson (1956). Before proceeding to discuss our results it is important to explain that a change of nomenclature is necessary regarding the genus Lophomonas (Galarneault \& Leifson). In 1860 Stein gave the name Lophomonas to a genus of protozoa found in the cockroach colon; see Wenyon (1926) and Kudo (1954) concerning current usage of the name. Under Rule 24 (see also Principle 3 and Opinion 14) of the International Code of Nomenclature of Bacteria and Viruses (1958) such a name must not be used in bacteriology because it is a 'later homonym of the name 
of a protozoa taxon'. We propose the name Comamonas (Latinized Greek: Comaa lock of hair, and monas-a unit) to replace Lophomonas in bacteriology. The type species of Lophomonas, $L$. alcaligenes proposed by Galameault \& Leifson was presumably a new combination of the name Vibrio alcaligenes (Lehmann \& Neumann, 1931) but this is not only uncertain but also invalid in view of certain differences in definition between Lophomonas and Vibrio alcaligenes (see Park, $1961 a$ ). We therefore designate the type species of Comamonas as $C$. percolans (Mudd \& Warren, 1923) nov. comb. Cultures of the type strain of this species are maintained as ATCC 8461, NCTC 1937 and NCIB 8193. It is interesting to note here that Bergey's Manual (1957) suggests that Vibrio percolans and V. alcaligenes may be synonymous but no definite information on this point is given.

Strain 8194 is clearly distinct from Vibrio comma and as Hugh \& Leifson (1953) have pointed out, there seems no justification for retaining this strain in the genus Vibrio. We see no reason why this organism should not be reclassified as a strain of Pseudomonas fluorescens. See Rhodes (1959) \& Park (1961 a) for comparable studies upon other strains of $\boldsymbol{P}$. fluorescens.

The organisms of our third group gave either negative or weak positive results in most of the tests tried, and because they resembled each other in this respect we consider them sufficiently alike to be included in the genus Comamonas. Upon the available evidence we cannot decide whether only one species. i.e. Comamonas percolans, is represented but this seems probable. Certain variations between strains and even within single strains were noticeable in this group and these suggest a gradation toward the typical Pseudomonas. Strain 8250 displayed an ability to utilize various aromatic compounds, while strain 2581 showed some evidence of carbohydrate attack. Similar but more marked gradations towards Pseudomonas have been noted independently in other strains of Comamonas by both authors, e.g. Park $(1961 a)$. We thus conclude that we can detect in Comamonas a continuation of the trend towards inactivity, as judged by the biochemical tests currently used, that was observed by Rhodes (1959) in the phytopathogenic strains of Pseudomonas. None of the Comamonas strains examined in this work had any history of pathogenicity, but the production of yellow pigment by 2581 (notably on milk agar) is of interest in this connexion. In spite of these considerations we feel that it is taxonomically useful to place in a separate genus, Comamonas, those polarly flagellate bacteria that neither produce a compound which fluoresces under u.v. nor show any clearly defined attack on carbohydrates.

The three so-called vibrios of Gray \& Thornton (1928), strains 8194, 2581, and 2582, gave different results in some cases from those originally reported for these strains. Of chief interest is probably the failure of the phenol-utilizing Vibrio cyclosites (2581) to utilize phenol in our test. It is to be expected, however, that after $\mathbf{3 0}$ years of laboratory maintenance these strains might show some changes in their reactions. We consider that although such changes may have occurred, the strains currently labelled as $V$. cyclosites, $V$. neocistes and $V$. cuneatus represent Gray \& Thornton's original isolates. Gray \& Thornton's classification was acknowledged to be 'one of convenience only and its temporary nature recognized'; over reliance upon their results from diagnostic tests is probably best avoided.

The utilization of oxalate by strain 8193 recorded above indicates a possible relationship with those oxalate decomposers of the Comamonas type reported 
by Bhat \& Barker (1948) and Jayasuriya (1955). In view of our recommendation to rename this organism Comamonas percolans as type species of the genus, it is important also to note here that Leifson \& Hugh (1953) and R.W.A.P., using cultures ATCC 8461 and NCTC 1937, respectively, found that it reduced nitrate to nitrite, whereas Mudd \& Warren (1923) and G.H.G.D., using the original isolate and NCIB 8193, respectively, found no nitrate reduction. The isolation of a peritrichous variant by Leifson \& Hugh (1953) has already been mentioned.

Strain 8250 exemplifies some of the taxonomic difficulties which organisms of this type may create. If polar flagellation had not been detected the strain could have been classified as an Alcaligenes or Protaminobacter species or as Achromobacter paroulus, to quote only a few of the possibilities available in Bergey's Manual (1957). Possible relationship to the genus Acetomonas (Shimwell et al. 1960) was also suspected, but Dr J. G. Carr kindly examined the organism and confirmed that classification in Acetomonas or Acetobacter was unjustified. (Note: Dr Carr also confirmed the lack of motility in the strain supplied to him by G.H.G.D., and did not detect any acid production from ethanol although the strain did produce irisation on ethanol-chalk agar and grew with ethanol as sole carbon source.)

The main object of this study was to define more accurately the genus Vibrio. Our results show that the strains we studied include a clear-cut and compact group, all basically the same as V. comma in morphological, cultural and biochemical characters. The overall similarity of the members of this group leads us to conclude that they are members of a single species; the conclusion drawn by Sneath \& Cowan (1958) that the genus Vibrio might reasonably be downgraded to species rank is of interest in this context.

In Table 4 we have listed certain characters which may have, or are commonly considered to have, diagnostic value in differentiating Vibrio from other polar flagellate bacteria. The closest similarity occurs between Vibrio and Aeromonas (see Park, 1961 $a$ ) and the existence of anaerogenic strains of Aeromonas (Crawford, 1954 ; Pivnick \& Sabina, 1957 ; Park, 1961 a) further complicates their differentiation. Two characters, pleomorphism and sensitivity to $0 / 129$, usually found in Vibrio but not in Aeromonas strains appear to be of possible diagnostic value and require further assessment.

The distinctive morphology observed in all but one of our Vibrio strains appears to be of diagnostic value when present. Its absence, however, does not allow one to exclude an organism from Vibrio as it is well known that strains of V. comma may exist as almost straight rods (see Pollitzer, 1955). Some bacteria that are biochemically very different from $V$. comma also show this distinctive morphology (Smith \& Taylor, 1919; Spencer, 1955; Bryant \& Small, 1956; Deas, 1960; Park, $1961 b$ ). It is difficult to decide whether these organisms should be regarded as close relatives of $V$. comma on morphological grounds, or as not related to it because of their distinct biochemical characters. The presence merely of somatic curvature is of no diagnostic value. It is known to occur in strains of many genera, e.g. Pseudomonas, Aeromonas, Comamonas, Selenomonas, etc.

Susceptibility to the vibriostatic agent $0 / 129$ first used in systematic work by Shewan, Hodgkiss \& Liston (1954) seems, like the distinctive morphology, to be of positive value when present, but of no value when absent. The report by Rhodes (1959) that two NCTC strains of Aeromonas were sensitive to a soluble phosphate 
derivative of $0 / 129$ complicates the issue. It may be that results obtained with the phosphate derivative are not strictly comparable with ours. Whatever the explanation, the fact remains that the distinction between these two genera is not clear. (Note: the authors recognize the value of simple diagnostic procedures in routine identification of bacteria, but suggest that the above comments show how important it is to base such procedures upon sound taxonomic knowledge of the organisms concerned. It is certain that reliance upon single characters, however well authenticated, can lead to errors being made. The literature of Vibrio is largely concerned with diagnosis rather than with taxonomy.)

Finally, we should like to draw attention to an important aspect of the work carried out in Asia upon the identification and classification of Vibrio. The term 'cholera and cholera-like vibrios' frequently occurs in this literature and there is good reason to doubt the true Vibrio nature of some of the bacteria studied. The definition of Vibrio commonly applied (Taylor, Pandit \& Reed, 1937) and the isolation techniques used, would not guarantee exclusion of all organisms which we now recognize as Comamonas, Pseudomonas or Aeromonas strains. The study of Pandit \& Maitra (1938) is a good example. The 'water-vibrios' of Heiberg's (1935) Group VI (non-fermenting strains), the 'non-fermenters' of Gardner \& Venkatraman (1935), and Linton's chemical group III (see Linton, 1940) are also interesting in this context. It is difficult in most cases to tell whether the organisms which showed no reaction with the cholera somatic $O$ antigen (e.g. Taylor \& Ahuja, 1938) were in fact non-vibrios or just non-cholera vibrios. It is similarly difficult to analyse the results of Jackson (1948) who isolated 49 strains of 'vibrio' from 32 of 43 English surface-water samples (cf. Park, 1961 $a$ ). The serological heterogeneity of most of these strains does not necessarily exclude them from Vibrio, but neither do the isolation methods nor biochemical results reported ensure that all the strains examined were vibrios. In the circumstances it is easy to see why such workers as Gray \& Thornton (1928) allotted dubious organisms to Vibrio.

Only by making closer and more detailed taxonomic studies of organisms that workers at present consider as Vibrio spp., and by unifying the diverse interests in vibrio-like bacteria from various habitats, e.g., marine, soil, animal, human, can we hope to rectify the situation that exists and has been responsible for the inclusion in the genus Vibrio of Bergey's Manual (1957) of such a heterogeneous collection of bacteria.

The authors wish to thank Dr P. F. D'Arcy of Allen and Hanbury for a gift of vibriostatic agent $0 / 129$.

\section{REFERENCES}

Aluen, P. W. (1918). A simple method for the classification of bacteria as to diastase production. J. Bact. 3, 15.

BarritT, M. M. (1936). The intensification of the Voges-Proskauer reaction by the addition of $\alpha$-naphthol. J. Path. Bact. 42, 441.

BEAM, W. E. (1959). Effect of excess nitrite on tests for indole and the cholera red reaction. J. Bact. 77, 328.

Bergey's Manual of Determinative Bacteriology (1957). 7th ed. Ed. R. S. BreEd, E. G. D. Murray, \& N. R. Smith. London: Baillière, Tindall and Cox.

Bhat, J. V. \& Barker, H. A. (1948). Studies on a new oxalate decomposing bacterium, Vibrio oxaliticus. J. Bact. 55, 859. 
Bisset, K. A. (1952). Bacteria. Edinburgh: Livingstone.

Bryant, M. P. \& Smald, N. (1956). Characteristics of two new genera of anaerobic curved rods isolated from the rumen of cattle. J. Bact. 72, 22.

Buchner (1885). Cited in Bergey's Manual (1957).

CaIN, R. B. (1961). The metabolism of protocatechuic acid by a vibrio. Biochem. $J$. 79, 298.

Carlquist, P. R. (1956). A biochemical test for separating paracolon groups. J. Bact. 71, 339.

Christensen, W. B. (1946). Urea decomposition as a means of differentiating Proteus and paracolon cultures from each other and from Salmonella and Shigella types. J. Bact. 52,461 .

Coluns, M. A. \& Hammer, B. W. (1934). Types of lipolysis brought about by bacteria as shown by Nile-Blue sulphate. J. Bact. 27, 487.

Conv, H. J. \& Wolfe, G. E. (1938). The flagellation of bacteria. Science, 87, 288.

Crawford, I. P. (1954). A new fermentative pseudomonad, Pseudomonas formicans, n.sp. J. Bact. 68, 734.

Davis, G. H. G. \& Freer, J. H. (1960). Studies upon an oral aerobic actinomycete. J. gen. Microbiol. 23, 163.

Deas, D. W. (1960). Observations on swine dysentery and associated vibrios. Vet. Rec. 72, 65.

Evans, D. G. (1947). The production by certain species of Clostridium of enzymes disintegrating hide powder. J. gen. Microbiol. 1, 378.

Felsenfeld, O. (1944). The lecithinase activity of Vibrio comma and the El Tor vibrio. J. Bact. 48, 155.

Frazier, W. C. (1926). A method for the detection of changes in gelatin due to bacteria. J. infect. Dis. 39, 302.

Gaby, W. L. \& Hadley, C. (1957). Practical laboratory test for the identification of Pseudomonas aeruginosa. J. Bact. 74, 356.

Galarneault, T. P. \& Leifson, E. (1956). Taxonomy of Lophomonas n.gen. Canad. J. Microbiol. 2, 102.

Gardner, A. D. \& Venkatraman, K. V. (1935). The antigens of the cholera group of vibrios. J. Hyg., Camb. 35, 262.

Georgia, F. R. \& Poe, C. F. (1931). Study of bacterial fluorescence in various media. 1. Inorganic substances necessary for bacterial fluorescence. J. Bact. $22,349$.

Gessard, C. (1891). Des races du Bacille pyocyanique. Ann. Inst. Pasteur, 5, 65.

Gray, P. H. H. \& Thornton, H. G. (1928). Soil bacteria that decompose certain aromatic compounds. Zbl. Bakt. (2. Abt.), 73, 74.

HappoLD, F. C. \& KEY, A. (1932). The bacterial purification of gasworks liquors. The action of the liquors on the bacterial flora of sewage. J. Hyg., Camb. 32, 573.

Hastings, E. G. (1904). The action of various classes of bacteria on casein as shown by milk agar plates. Zbl. Bakt. (2. Abt.), 12, 590.

HaYnes, W. C. (1951). Pseudomonas aeruginosa-its characterization and identification. J. gen. Microbiol. 5, 938.

Heiberg, B. (1935). On the Classification of Vibrio cholerae and the Cholera-like Vibrios. Copenhagen: Busck.

Henrici, A. T. (1925). A statistical study of the form and growth of the cholera vibrio. J. infect. Dis. 37, 75.

HUGH, R. \& Leifson, E. (1953). The taxonomic significance of fermentative versus oxidative metabolism of carbohydrates by various Gram negative bacteria. J. Bact. 66, 24.

International Code of Nomenclature of Bacteria and Viruses (1958). Edited by the editorial Board of the International Committee on Bacteriological Nomenclature. Ames, Iowa: Iowa State College Press.

JACKson, R. (1048). The incidence and character of vibrios in British waters. J. gen. Microbiol. 2, 239.

JAYASURIYA, G. C. N. (1955). The isolation and characteristics of an oxalate decomposing organism. J. gen. Microbiol. 12, 419. 
Jeynes, M. H. (1961). The growth and division of bacterial protoplasts. J. Exp. Cell Res. 24, 255.

KocH, R. (1886). The etiology of cholera. (Paper read at the conference held at Berlin for the discussion of the cholera question, July, 1884.) Translation from the German in: 'Recent essays on bacteria in relation to disease.' Nero Sydenham Soc. 115, 325.

Kovacs, N. (1956). Identification of Pseudomonas pyocyanea by the oxidase reaction. Nature, Lond. 178, 708.

Kuno, R. R. (1954). Protozoology. 4th ed. Springfield, Illinois: Thomas.

Lehmann, K. B. \& Neumann, R. O. (1931). Bacteriology, especially Determinative Bacteriology, 7th ed. vol. 2. (English translation, Breed, R.S.) Stechert, New York.

Lerrfon, E. (1960). Atlas of Bacterial Flagellation. New York: Academic Press.

LEIFSON, F. \& HUGH, R. (1953). Variation in shape and arrangement of bacterial flagella. J. Bact. 65, 263.

Linton, R. W. (1940). The chemistry and serology of the vibrios. Bact. Rev. 4, 261.

LrU, P. (1952). Utilization of carbohydrates by Pseudomonas aeruginosa. J. Bact. 64, 773.

MAckie, T. J. \& McCARTNey, J. E. (1953). Handbook of 'Practical Bacteriology, 9th ed. Edinburgh: Livingstone.

Meitert, E., Meitert, T. \& Horodniceanu, T. (1960). Tests supplementaires d'identification du $B$. pseudomonas pyocyanea (Ps. aeruginosa). Réaction de la cytochromeoxydase et le comportement sur le milieu avec triphenyltetrazolium-chlorid. Arch. roum. Path. exp. Microbiol. 19, 149.

MudD, S. \& Warnen, S. (1923). A readily cultivable vibrio, filterable through Berkefeld ' $V$ ' candles, Vibrio percolans (new species). J. Bact. 8, 447.

Narayanan, E. K. \& Menon, P. S. (1952). Enzymes of V. cholerae. Nature, Lond. 170, 621.

OrcutT, F. S. \& Nutring, L. A. (1942). The possibility of false interpretations in tests for acid production from carbohydrates due to peptone decomposition. J. Bact. 44, 147 .

Pandit, S. R. \& Martra, N. M. (1988). Vibrios in natural water sources in Assam. Indian J. med. Res. 26, 34.

PARK, R. W. A. (1961 a). A study of certain heterotrophic polarly flagellate water bacteria: Aeromonas, Pseudomonas and Lophomonas. J. gen. Microbiol. 27, 121.

Park, R. W. A. (1961b). A note on the systematic position of Vibrio fetus. J. appl. Bact. 24, i.

Pitzurra, M. \& SzYbalski, W. (1959). Formation and multiplication of spheroplasts of Escherichia coli in the presence of lithium chloride. J. Bact. 77, 614.

Pivnick, H. \& Sabina, L. R. (1957). Studies of Aeromonas formicans Crawford, comb.nov. from soluble oil emulsions. $J$. Bact. 73, 247 .

Poulitzer, R. (1955). Cholera studies. 3. Bacteriology. Bull. World Hith Org. 12, 777.

Rhodes, M. E. (1959). The characterization of Pseudomonas fluorescens. J. gen. Microbiol. 21, 221.

Shaw, C. \& Clarke, P. H. (1955). Biochemical classification of Proteus and Providence cultures. J. gen. Microbiol. 13, 155.

Shewan, J. M., Hodgriss, W. \& Liston, J. (1954). A method for the rapid differentiation of certain non-pathogenic, asporogenous bacilli. Nature, Lond. 173, 208.

Shimwell, J. L., Carr, J. G. \& Rhodes, M. E. (1960). Differentiation of Acetomonas and Pseudomonas. J. gen. Microbiol. 23, 283.

Simon, R. D. (1956). The use of fermentation reactions and pigment production to differentiate between types of Pseudomonas pyocyanea and other Pseudomonas species especially fluorescens. Brit. J. exp. Path. 37, 494.

Smith, T. \& TAXLOR, M. S. (1919). Some morphological and biological characters of the spirilla (Vibrio fetus, n.sp.) associated with disease of the fetal membrane in cattle. J. exp. Med. 30, 299.

Sneath, P. H. A. \& Cowan, S. T. (1958). An electro-taxonomic survey of bacteria. $J$. gen. Microbiol. 19, 551.

Spencer, R. (1955). The taxonomy of certain luminous bacteria. J. gen. Microbiol. 13, 111. 


\section{Taxonomy of Vibrios}

StEIN, F. (1860). Vortrag über die bisher unbekannt gebliebene Leucophrys patula Ehbg. und über zwei neue Infusioriengattungen Gyrocorys und Lophomonas. Sitz. K. Böhm. Ges. Wiss. 1, 44.

Szturm-Rubinsten, S., Piéchaud, D. \& Piéchaud, M. (1960). De quelque caractères des vibrions saprophytes. Ann. Inst. Pasteur, 99, 309.

TAYLOR, J. \& AHUJA, M. L. (1938). Incidence and characters of vibrios in waters in Northern India. Indian J. med. Res. 26, 1.

Taylor, J., Pandit, S. R. \& Reed, W. D. B. (1937). A study of the vibrio group and its relation to cholera. Indian J. med. Res. $24,031$.

Thibault, P. \& Le Minor, L. (1957). Méthodes simples de recherche de la lysine-décarboxylase et de la tryptophane-desaminase à l'aide des milieux pour différentiation rapide des entérobactériacées. Ann. Inst. Pasteur, 92, 551.

Topley and Wilson's Principles of Bacteriology and Immunity (1955). 4th ed. Revised by Wilson, G. S. \& Miles, A. A. London: Arnold.

Wenyon, C. M. (1926). Protozoology. London: Baillière, Tindall and Cox.

Wrurs, A. T. (1960). The lipolytic activity of some clostridia. J. Path. Bact. 80, 379.

ZoBexl, C. E. (1932). Factors influencing the reduction of nitrates and nitrites by bacteria in semi-solid media. J. Bact. 24, 273.

\section{EXPLANATION OF PLATE}

Electronmicrographs; shadowed gold-palladium $(60: 40)$ mixture. From $24 \mathrm{hr}$. growth on nutrient agar.

Figs. 1, 7. Strain 8563 (Vibrio proteus) showing straight and curved rods, spheroplasts and long dividing forms, single and bipolar monotrichous flagellation. Fig. 1, $\times c .3000 ;$ Fig. 7, $\times c .4500$.

Fig. 2. Strain 30 (Vibrio paracholerae) showing rod forms and a spheroplast. $\times$ c. 4000 .

Fig. 3. Strain 2582 (Vibrio neocistes, Comamonas sp.) showing bipolar flagellation as exhibited by this strain and strain $2581 . \times c .4500$.

Fig. 4. Strain 8194 (Vibrio cuneatus, Pseudomonas fluorescens). $\times$ c. 6000.

Fig. 5. Strain 1937 (Vibrio percolans, Comamonas sp.). $\times c .15,000$.

Fig. 6. Strain 9239 (Vibrio alcaligenes, Comamonas sp.). $\times$ c. 5000.

Flagellation:

$1=1$ or rarely 2 , polar

$M=1$ or several, polar
Key to Tables 1-3

$\mathbf{L}=$ at one or both poles

$+=$ positive

$\pm=$ weak, slow or late reaction or growth

Fractional figures $=$ number of strains positive/number tested (in some cases $\pm /$ tested).

$-\quad=$ no reaction, growth, etc.

$A=$ excess acid

$\mathrm{F}=$ fermentation

Al. = alkaline reaction in open tube

NG $=$ no growth

$\mathbf{Y G}=$ yellow-green

$\mathbf{Y}=$ yellow

Notes.

(a) All strains examined were Gram-negative.

(b) In R.W.A.P. results, all strains cleared tributyrin, attacked malonate (Shaw \& Clarke), grew at $30^{\circ}$ and in $0.5 \%$ and $1 \% \mathrm{NaCl}$, and were susceptible to Terramycin 10 units and Chloramphenicol 100 units. None gave positive Eijkman reaction, utilized or produced acid from dulcitol, grew at $45^{\circ}$ or in $9 \% \mathrm{NaCl}$, produced pyocyanin, or gas.

(c) In G.H.G.D. results, all strains grew at $25^{\circ}$ and $30^{\circ}$; all utilized succinate and citrate. None produced acid from dulcitol, sorbitol, raffinose or inulin. None produced gas from glucose, gave V.P. + reaction, grew at $44^{\circ}$, produced dihydroxy-acetone from glycerol, were susceptible to bacitracin 5.5 units, oleandomycin $5 \mu \mathrm{g}$., penicillin 2.5 and 1 units. All were susceptible to Terramycin 100 and 25 units.

(d) In Table 1, under 'Acid production (and utilization of) :',+ \pm and - refer to acid production only. 

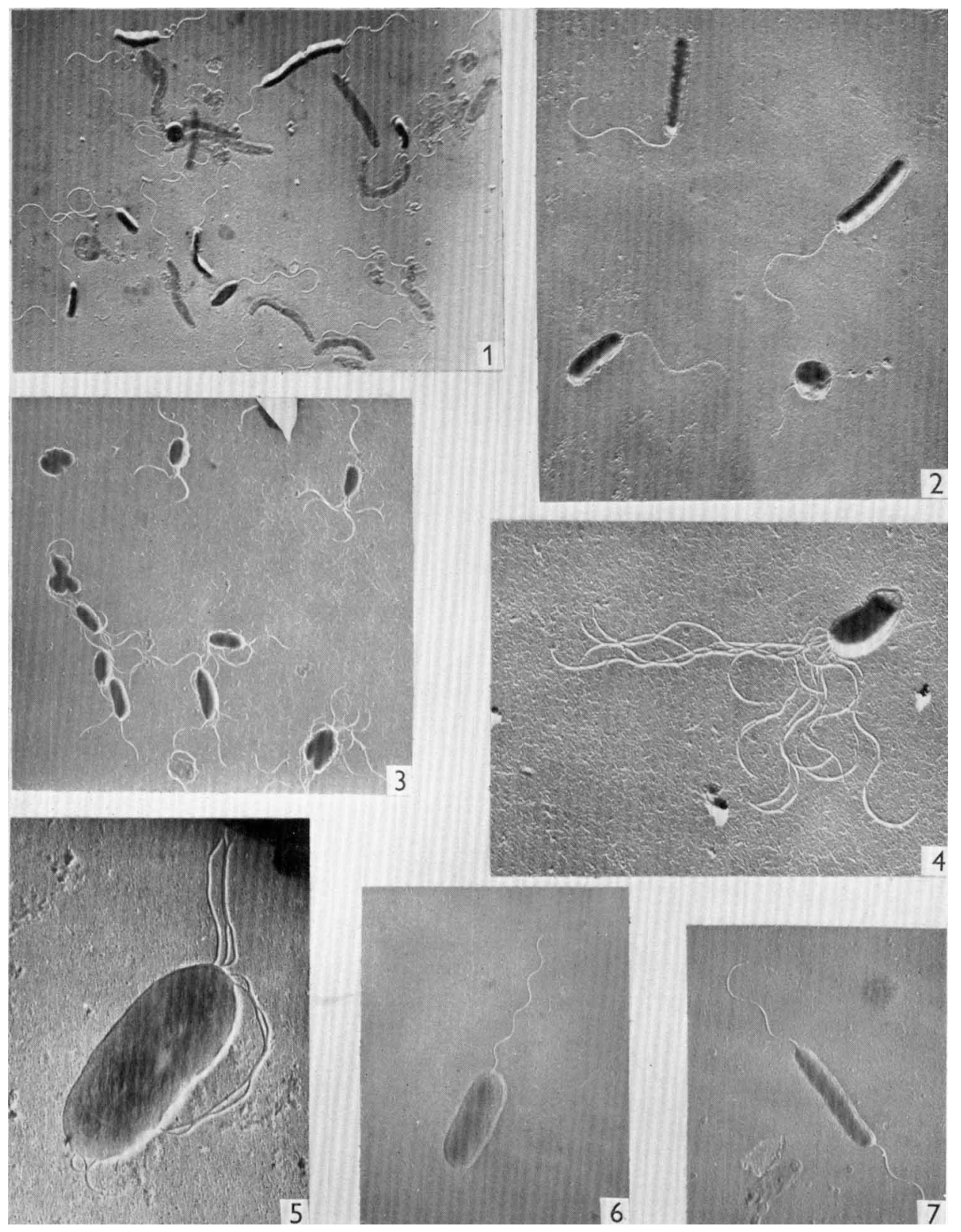